\title{
Effect of COVID-19 Disruptions on Young Adults' Affect and Substance Use in Daily Life
}

\author{
Lauren M. Papp \\ University of Wisconsin-Madison \\ Chrystyna D. Kouros \\ Southern Methodist University
}

\section{Psychology of Addictive Behaviors}

In press, March 2021

(C) 2021, American Psychological Association. This paper is not the copy of record and may not exactly replicate the final, authoritative version of the article. Please do not copy or cite without authors' permission. The final article will be available, upon publication, via its DOI: 10.1037/adb0000748

Lauren M. Papp, Department of Human Development and Family Studies, University of Wisconsin-Madison. Chrystyna D. Kouros, Department of Psychology, Southern Methodist University.

Research reported in this publication was supported by the National Institute on Drug Abuse of the National Institutes of Health under Award Number R01DA042093. The content is solely the responsibility of the authors and does not necessarily represent the official views of the National Institutes of Health. The associations tested in the present study have not been examined in any previous article or interpreted for any prior dissemination outlets. We gratefully acknowledge the study's participants and research assistants, especially Alexandra Barringer and Shari Blumenstock.

Correspondence concerning this article should be addressed to Lauren M. Papp, Department of Human Development and Family Studies, University of Wisconsin-Madison, 1300 Linden Drive, Madison, WI 53706. E-mail: papp@wisc.edu 


\begin{abstract}
Objective: Guided by accounts of adjustment in daily life as a key indicator of health, the current study examined prospective changes in young adults' emotions and substance behaviors assessed during a normative baseline period and during the acute COVID-19 disruption period in late March/early April 2020. The COVID-19 assessment also collected psychosocial risk factors expected to moderate changes in adjustment across time. Method: Participants included 295 young adults (70.8\% female; ages $18-21$ at baseline), drawn from an ongoing study of daily behaviors and health in college life that oversampled for recent substance behaviors, who completed both the baseline and COVID-19 assessments. Hypotheses were tested using analyses of repeated-measures data that included covariates of length of time between assessments and sampling group status. Results: Direct tests in support of hypotheses indicated an increase in negative affect $(d=.67, p<.001)$, and greater alcohol use $(d=.75, p<.001)$ and marijuana use $(d=.58, p<.001)$, in daily life across time. Levels of positive affect $(d=.08, p>.05)$, nicotine use $(d=.01, p>.05)$, and prescription drug misuse $(d=.003, p>.05)$ did not reliably change in tests of direct models. Moderation tests indicated several risk factors for experiencing steeper increases in negative affect, and increased likelihood of marijuana and nicotine use, in daily life across time. Conclusions: Findings offer implications for future research and clinical efforts to improve young adult adjustment in response to the pandemic.
\end{abstract}

Keywords: COVID-19, young adults, affect, substance use, daily life, risk factors

\title{
Public Significance Statement
}

The present findings contribute novel information to address an urgent need to understand young-adult adjustment and health at the time of the coronavirus disruptions in the United States. Prospective analyses indicated that participants, on average, experienced higher levels of negative affect and engaged in more alcohol and marijuana use in daily life during the disruption 
period than they previously had. Psychosocial risks, including higher levels of loneliness, financial strain, worry about health, and marijuana craving, made some young adults more vulnerable to experiencing increased negative affect and greater use of substances over time and, accordingly, warrant continued attention in research and applied efforts. 


\section{Effect of COVID-19 Disruptions on Young Adults' Affect and Substance Use in Daily Life}

The ongoing pandemic related to coronavirus disease 2019 (COVID-19) has drastically disrupted daily life, resulting in changes to behaviors, emotions, and stressful experiences that are likely to hold lasting health implications for individuals in key developmental periods. Young-adult college students, in particular, needed to immediately navigate one or more changes in education, social, employment, or living situations. Their responses to these disruptions are expected to hold concurrent and enduring significance, in light of evidence that behavioral health in young adulthood (substance use and mental health, in particular) is a crucial predictor of later adult health and well-being (Brown et al., 2008; Stroud et al., 2015). As colleges across the nation navigate to provide virtual and in-person support for their students, translational knowledge is urgently needed to support prevention and treatment of problems associated with COVID-19 transitions and the evolving public health situation. Indeed, problematic emotions and behaviors, such as elevated negativity or binge drinking, that emerge in day-to-day life have the potential to interfere with academics (Greene \& Maggs, 2017) and have been implicated in longer-term mental health and substance use (Jennison, 2004; Linden-Carmichael et al., 2015).

Early on, scholars anticipated increases in mental health distress (Gruber et al., 2020) and alcohol misuse (Clay \& Parker, 2020) in the isolating and stressful context of the coronavirus pandemic that could impact public health more broadly. Initial reports (Rodriguez et al., 2020; Twenge \& Joiner, 2020) suggest that mental distress and problem drinking have increased among U.S. adults due to the COVID-19 pandemic and related changes to daily life, such as staying at home, constant news coverage, and economic uncertainty. Although limited, evidence indicates mounting adjustment problems among young adults, as well: A study examining wellbeing of college students in China (Cao et al., 2020) found higher levels of self-rated anxiety among those who reported greater economic and academic worry, more personal impact of the 
virus, and lower social support. Of note, Lechner and colleagues (2020) documented increases in U.S.-based college students' alcohol consumption from one week before a campus closed to one week after it closed. Furthermore, protective factors were identified in that greater social support was linked to less alcohol consumption over the time period. However, that study's assessments of the two separate weeks of drinking both occurred retrospectively, leaving open the possibility that participant reports of baseline drinking were biased by their pandemic experiences. In sum, research is needed to understand how the COVID-19 crisis has directly changed young-adult college students' affect and behaviors (beyond alcohol use alone), and to identify characteristics that place young adults' adjustment in daily life at risk.

Guided by empirical and theoretical models of adjustment in daily life as central to individuals' health and development (Bronfenbrenner \& Morris, 2006; Greene \& Maggs, 2017), the current study examined changes in young adults' affect and substance use behaviors early in the pandemic during the period of acute COVID-19 disruptions in the United States. We focus on global mood (positive and negative affect) along with salient substance behaviors in this age period, including use of alcohol, marijuana, and nicotine, and misuse of prescription medications. Even in typical times, the college years during young adulthood reflect a particularly risky period in the life course for elevated mental health distress (Lee et al., 2017) and substance problems (White et al., 2006). By drawing on data obtained from intensive sampling procedures that occurred prior to the coronavirus outbreak, and then reassessing the same participants' current emotions and recent behaviors early in the pandemic (March/April 2020), the design allows for prospective investigation of direct changes in adjustment in daily life as a result of COVID-19 disruptions. 
The first research aim was to test direct COVID-19-related changes in emotional and behavioral adjustment in daily life. Due to transitions and heightened stress (Vinkers et al., 2020) imposed by the pandemic, we hypothesized that young adults would experience greater negative affect and lower positive affect, along with increased occurrence of substance use (i.e., alcohol, nicotine, marijuana, prescription misuse), in daily life over time. Given the unmatched period under investigation, we did not make differential predictions for the various substance indicators.

The second research aim was to identify risk factors that were expected to moderate the extent to which young adults' adjustment in daily life changed across assessments. Stress and coping models (Metzger et al., 2017) argue that those with weaker psychosocial resources will respond in more hazardous ways to the demands of this period. For example, in the context of the pandemic, young adults with greater financial and social supports would be expected to show less problematic change in their adjustment across time. In contrast, those who were more concerned about illness and the negative impact of illness might have shown more declines in adjustment. Accordingly, we hypothesized steeper increases in negative affect (along with steeper declines in positive affect) and greater increases in substance use among individuals who reported greater loneliness, financial strain, and anxiety related to health and to becoming ill at the time of COVID-19 disruptions. In addition, more frequent use of alcohol and other drugs has been linked to greater negative affect (via the self-medication hypothesis; e.g., Dixit \& Crum, 2000) and to increased craving and problematic use of substances (consistent with models of polysubstance use; e.g., Morley et al., 2017). Thus, we expected significantly steeper increases in adjustment problems over time (more negative affect, greater substance use in daily life) for those reporting higher levels of drinking-related consequences and marijuana craving at the time of the COVID-19 disruptions. 


\section{Method}

\section{Procedures and Participants}

Data are drawn from an ongoing study funded by the National Institute on Drug Abuse to investigate daily behaviors and health in college life. The baseline assessment was conducted between September 2017 and September 2019 and included 355 participants oversampled for recent prescription drug misuse. Participants at a large university in the Midwestern U.S. were initially recruited via flyers and announcements (e.g., newspaper ads, emails to enrolled students) that stated, "We are particularly interested in how people use prescription medications." Prospective participants completed an online screening and a telephone call was scheduled to confirm eligibility. Inclusion criteria were (a) being enrolled as a freshman or sophomore (verified against Registrar database); (b) being 18 to 21 years of age; and, for the risk group of participants, (c) endorsing recent prescription drug misuse of one or more medication; the screening measure is described in Papp, Barringer et al. (2020) and Papp, Kouros, and Curtin (2020). The recruitment and enrollment process oversampled for prescription drug misuse behavior, given that a central aim of the larger project is to identify situations and factors that predict the occurrence of prescription drug misuse in daily life. The study included 300 participants from the risk group and 55 participants who did not endorse recent prescription drug misuse during screening (the non-risk comparison group). To minimize any differences in recruitment between groups, the non-risk participants were enrolled simultaneously with the risk participants throughout the recruitment period.

For the study baseline assessment, participants attended two lab sessions that were scheduled an average of 35 days apart and were trained to complete reporting procedures in daily life between the sessions. During the first session, participants completed informed consent 
procedures and survey measures and were trained to use an iPod Touch application designed specifically for the present research; they chose a private password to access the application and completed a sample report in the lab. Access to all other device features was restricted. The scheduled reporting period started the following day. Although the typical reporting period was scheduled for the 28 days following the first lab session, some participants continued reporting until they returned their device at the second lab session; reports obtained across all days were retained in the current analyses to provide the most representative view of daily life.

Under the planned study design, online follow-up surveys are collected every six months for two years after the baseline assessment and are continuing. Prior to the study, university institutional review board approval and a National Institutes of Health Certificate of Confidentiality were obtained. During the baseline assessment, participants received their choice of electronic or check payments. Compensation (in US\$) included $\$ 75$ for session 1, \$84 for reporting in daily life (prorated for partial completion), $\$ 55$ for session 2 , and a $\$ 36$ bonus incentive for maintaining compliance across the planned reporting period.

In March 2020, we invited all participants in the broader study to complete an additional online survey to understand their experiences and daily adjustment at the onset of COVID-19 disruptions. Participants were compensated \$20 for completing this one-time survey. All 355 study participants received an invitation and one reminder (if needed) to complete the survey. Most ( $n=295 ; 83.1 \%$ ) of the broader study participants completed the COVID-19 assessment between March 27, 2020, and April 6, 2020, at which point the survey was closed; these respondents comprise the current analytic sample.

During the acute COVID-19 assessment period, nearly all respondents were members of a campus community that was limiting access to residence halls and transitioning courses online. 
Data provided by the campus Registrar's Office indicated that 14 participants $(4.7 \%$ of the current sample) were not enrolled during the Spring 2020 semester. Specifically, 9 participants ( 8 risk participants and 1 non-risk participant) had graduated, and 5 participants ( 4 risk participants and 1 non-risk participant) had withdrawn for medical or personal reasons, prior to the COVID-19 assessment. Due to these low frequencies, student status was not considered as a covariate. Risk-group status was not associated with responding to the COVID-19 assessment $\left(83.3 \%\right.$ of risk participants and $81.8 \%$ of non-risk participants responded), $\chi^{2}(1)=0.08, p=.78$.

Demographics were collected at the baseline assessment. At study enrollment, the current 295 participants reported an average age of 19.5 years $(S D=0.71)$. The majority $(70.8 \%)$ identified as female, and slightly more than half (54.6\%) were freshmen. In terms of racial and ethnic background, nearly $7 \%$ reported Hispanic or Latinx background and $86.8 \%$ self-identified as White. The remaining participants (12.9\%) self-identified as American Indian/Alaska Native, Asian, Black or African American, Native Hawaiian or Pacific Islander, or reported multiple or other races (identities included $<3 \%$ of respondents); one $(0.3 \%)$ did not respond. Participants were ethnically and racially representative of the campus from which they were sampled.

\section{Measures}

Background substance problems. Background substance use was measured during the first lab session at baseline. Descriptive statistics are reported in Table 1.

The Rutgers Alcohol Problem Index (RAPI; White \& Labouvie, 1989) consists of 18 items that examine various consequences of alcohol use that could have been experienced recently (e.g., "neglected your responsibilities"). Following Neal et al. (2006), participants responded to each item using options of 0 (did not experience) or 1 (experienced at least one time in the last 3 months). Endorsed consequences were summed, with higher scores indicating 
greater alcohol use and alcohol-related consequences. In the present sample, $11.2 \%$ of participants had a score $\geq 8$, which indicates the need for clinical treatment.

The study assessed lifetime cigarette use using a series of questions from the Population Assessment of Tobacco and Health (PATH) Study (NIH, 2013). Participants who positively endorsed that they have ever smoked a cigarette, even one or two puffs, were classified as a Smoker and received the follow-up question: "How many cigarettes have you smoked in your entire life? A pack usually has 20 cigarettes in it." Response options ranged from 1 (1 or more puffs but never a whole cigarette) to 6 (100 or more cigarettes, 5 packs or more). The modal response was 1 , which was endorsed by $32.2 \%$ of the 177 participants classified as Smokers. Participants completed two versions of the 10-item Drug Abuse Screening Test (DAST10; Skinner, 1982), a measure of past-year drug use. The measure's standard instructions define "drugs" by having respondents consider nonmedical use of prescription medications, along with other drugs such as marijuana, cocaine, crack, meth, hallucinogens, and heroin; participants were explicitly instructed to exclude alcohol and tobacco from consideration. Given the broader project's recruitment, we modified the DAST-10 by having one version focused only on nonmedical use of prescriptions (excluding alcohol, tobacco, and the other drugs) and one version focused on the other drugs mentioned (excluding alcohol, tobacco, and nonmedical use of prescriptions). One item asked about any involvement with drugs other than those required for medical purposes. One item asked whether the respondent is always able to stop using drugs when they want to (reverse scored). Other items tapped potential consequences of drug use; a sample item is, "Have you engaged in illegal activities to obtain drugs?" (Options are Yes/No). Endorsed items were summed, with higher scores reflecting higher drug use. Scores of 1-2 indicate potential drug problems and scores of 3 and above indicate moderate to severe drug 
problems. In the current study, $52.9 \%$ of the sample had potential problems, and $19.8 \%$ had moderate to severe problems, with prescription drug misuse. Also, $50.5 \%$ of the sample had potential problems, and $29.5 \%$ had moderate to severe problems, related to other drug use.

Outcome variables. Participants' emotions and substance use behaviors were collected at baseline via ecological momentary assessment (EMA) reporting and during COVID-19 disruptions via an online survey.

Baseline assessment. The EMA protocol administered during baseline included both signal- and event-contingent assessments. Signal-contingent reporting involved responding to a device prompt sent within four time windows (8:00 a.m.-11:30 a.m., 11:30 a.m.-3:00 p.m., 3:00 p.m.-7:00 p.m., and 7:00 p.m.-11:00 p.m.); prompts were sent at varying times within each window across days. Participants were instructed to respond as soon as possible as appropriate. Participants were also trained to self-initiate a report any time they intended to take a medication listed in any way a doctor did not direct them to use it. Momentary report questions focused on participants' current location and social context and potential triggers of prescription drug misuse (e.g., mood states, pain, stressors, other substance behaviors). Signal- and event-based assessments were identical. A signal-contingent prompt was not sent within 2 hours after a selfinitiated report had been completed to reduce burden. If misuse intention of one or more of the medication classes was endorsed, participants were sent a brief follow-up 15 minutes later to assess misuse behaviors that might have occurred since the completion of the associated report; participants could delay responding to the follow-up for 15 minutes. All time-stamps of report and follow-up completion were automatically recorded. During the second lab session, participants returned their devices and completed additional measures. A research assistant then unlocked the device, downloaded the EMA reports to a secure server, and reset the devices. The 
present analyses draw from 23,972 momentary reports. The 295 participants returned an average of 81.82 reports $(S D=25.40$, range: $11-130)$ that were completed during reporting periods that spanned 4 to 37 days $(M=27.80, S D=6.12)$.

Each momentary assessment prompted participants to rate emotions taken from the Positive and Negative Affect Schedule-Expanded Form (PANAS-X; Watson \& Clark, 1999). Participants were instructed to rate the following 7 words/phrases according to how they felt "right now" using a scale of 1 (very slightly or not at all) to 5 (extremely): fearful (afraid, scared, frightened, nervous, jittery, shaky); hostile (angry, irritable, scornful, disgusted, loathing); guilt (ashamed, blameworthy, angry at self, disgusted with self, dissatisfied with self); sad (blue, downhearted, alone, lonely); jovial (happy, joyful, delighted, cheerful, excited, enthusiastic, lively, energetic); self-assured (proud, strong, confident, bold, daring, fearless); and attentive (alert, concentrating, determined). We created composites of Negative Affect (fearful, hostile, guilt, sad) and Positive Affect (jovial, self-assured, attentive) experienced in daily life by summing participant ratings of the respective emotions for each moment and then averaging across all reports completed by the participant. We calculated between-person reliability (i.e., $\mathrm{R}_{1 \mathrm{~F}}$; Cranford et al., 2006) on participants' average daily ratings of the affect composites; both were psychometrically sound $\left(\mathrm{R}_{1 \mathrm{~F}}=0.80\right.$ for Negative Affect, $\mathrm{R}_{1 \mathrm{~F}}=0.88$ for Positive Affect).

On each momentary report, participants were prompted, "In the past 15 minutes, have you...consumed alcohol?...used marijuana?...used nicotine?" They responded to each question with $0(\mathrm{No})$ or $1(\mathrm{Yes})$. We aggregated momentary reports to create day-level indicators for each substance behavior. These were summed across all EMA reports completed by each participant. Then these scores that reflected the total number of days each substance was used were divided 
by the number of reporting days completed by each participant, resulting in proportions of daily use of the substance behavior that could range from 0 to 1 .

Participants were asked on each momentary report, "Are you about to take a medication listed here in any way a doctor did not direct you to use it?" and were reminded about the ways this could occur. Participants indicated Yes or No for 4 classes of prescription drugs (with examples provided): sedatives or sleeping pills, tranquilizers or anxiety medications, stimulants, and pain relievers. When participants responded Yes to one or more of the intention questions, they received a follow-up prompt 15 minutes after this report was completed. Participants were asked, "Have you recently taken a medication listed here, in any way a doctor did not direct you to use it?" The same 4 medication classes and examples were presented. The current study used prescription drug misuse behavior from the follow-ups; responses to each item were recorded as $0(\mathrm{No})$ or $1(\mathrm{Yes})$. Multiple classes of misuse could be endorsed. These were recoded to indicate whether any misuse had occurred in the moment. Again, responses were aggregated across days and then summed and divided by the number of days of reporting completed (described above).

COVID-19 assessment. The online COVID-19 assessment presented the same PANAS-X emotion words/phrases and rating scale and instructed participants to indicate the extent of feeling each one right now. These ratings again were summed to create Negative Affect (4 items; Cronbach's alpha $=.75$ ) and Positive Affect (3 items; alpha $=.76)$ composites.

On the COVID-19 assessment, participants were asked, "Thinking back over the past two weeks, on how many days did you ... drink alcohol? ... use marijuana? ... use nicotine (e.g., cigarettes, e-cigs, chewing tobacco)? ... use a prescription medication in any way a doctor did not direct you to use it?" (The study's focal medications, examples, and definition of prescription 
drug misuse were provided.) To create daily indicators comparable to the substance use scores derived from the EMA responding prior to the pandemic, each response was divided by 14 days.

Moderators. Hypothesized moderators were assessed during the COVID-19 assessment. Brief scales were selected when available to minimize participant burden and encourage participation during challenging circumstances.

Participants rated their feelings of social isolation (e.g., "I feel left out") and companionship (e.g., “Can you find companionship when you want it?”). Items were drawn from the NIH Patient Reported Outcomes Measurement Information System (PROMIS; Cella et al., 2010; Jaremka et al., 2017), a collection of publicly available self-report health measures. Items were rated on a scale from 1 (never) to 5 (always). Scores on social isolation and companionship were moderately correlated $(r=-.57, p<.001)$ in the current sample. Companionship items were reverse scored and all items were summed to create a Loneliness composite ( 14 items; alpha $=$ .94), with higher scores reflecting greater feelings of disconnect from others as well as limited opportunities to engage with others in enjoyable activities.

Following Sarginson et al. (2014), participants indicated their current financial situation on a 5-point scale ( 1 = living very comfortably, $2=$ living quite comfortably, $3=$ just getting by, $4=$ finding it difficult to make ends meet, $5=$ not able to make ends meet). Participants also completed a checklist, adapted from Kiely et al. (2015) for a young adult sample, that assessed whether the following events occurred during the current situation due to lack of money: could not pay telephone or credit card bills on time, asked for financial help from friends or family, could not pay rent on time, pawned or sold something, was unable to heat home, went without meals, and asked for help from welfare or community organizations. Multiple events could be 
endorsed. Participants' rating and number of checklist items endorsed were correlated $(r=.67, p$ $<.001$ ); thus, we standardized and summed the scores, resulting in a Financial Strain composite.

Participants completed the short version of the Health Anxiety Inventory (Salkovskis et al., 2002), which has been used in clinical and non-clinical populations and demonstrates strong psychometric properties. For each item, participants were instructed to select the statement from a group of four that best described their feelings. The measure included two subscales typically analyzed separately: Health Anxiety (worry about health) and Negative Consequences (negative consequences of becoming ill). A sample item for Health Anxiety consists of: "I do not worry about my health; I occasionally worry about my health; I spend much of my time worrying about my health; I spend most of my time worrying about my health." A sample question for Negative Consequences includes: "A serious illness would ruin some aspects of my life; A serious illness would ruin many aspects of my life; A serious illness would ruin almost every aspect of my life; A serious illness would ruin every aspect of my life." In the current sample, subscale scores were positively correlated $(r=.30, p<.001)$. Internal consistency was satisfactory for Health Anxiety $(14$ items; alpha $=.90)$ and Negative Consequences $(4$ items; alpha $=.73)$.

Problems related to alcohol use were measured using the College Alcohol Problems Scale (Maddock et al., 2001). Four items assessing personal problems related to alcohol use were administered. Participants were prompted to answer the questions (Yes, No) thinking about the past two weeks; a sample item is, "As a result of drinking alcoholic beverages, I felt bad about myself." We augmented the measure by adding the following item "...felt less socially isolated." Endorsed items were summed to create an Alcohol Consequences score ( 5 items; alpha $=.74$ ).

The Marijuana Craving Questionnaire (Heishman et al., 2009) was administered. Participants rated on a scale from 1 (strongly disagree) to 7 (strongly agree) items that measured 
craving for marijuana along compulsivity ( 3 items; e.g., "I need to smoke marijuana now") and emotionality (3 items; e.g., "I would feel less anxious if I smoked marijuana right now") dimensions. Responses were summed to form a Marijuana Craving score (6 items; alpha $=.84$ ).

Covariates. The baseline phase of the broader study was conducted over a 2-year period. Accordingly, models accounted for variations in the length of time between participants' baseline assessment (date of first study visit) and their COVID-19 assessment (range: 192 - 914 days, $M=537.72, S D=184.17)$. Statistical models also accounted for risk group sampling.

\section{Analysis Plan}

As preliminary analyses, we examined descriptive statistics and explored possible sex differences in the outcome variables. We then tested differences in key study variables as a function of whether or not participants were enrolled into the broader study on the basis of their recent prescription drug use. When interpreting results from mean-difference tests, we report the corrected degrees of freedom when unequal variances across the two groups were indicated. We also examined construct validity of the indicators of substance use in daily life collected during study baseline by testing their associations with measures of background substance use and problems from the first lab session.

The repeated-measures data was analyzed using a multilevel modeling framework to test for mean differences in affect and substance use in daily life before (baseline assessment) and during the COVID-19 disruption period (online survey). Analyses were run using the Hierarchical Linear Modeling 8 (HLM8) software (Raudenbush et al., 2019). Specifically, models were run with time as a within-subject predictor at Level 1; a significant time slope indicates a significant mean increase or decrease (i.e., linear change) in the outcome over this time period. Models controlled for between-subject differences in time elapsed between 
assessments (numbers of days) and risk group ( $0=$ non-risk comparison group, $1=$ risk group $)$ by including them as predictors of the intercept at Level 2 (grand-mean centered). Negative affect and positive affect were modeled as continuous outcomes, whereas substance use indicators (ranged from 0 to 1 and reflected the proportion of days on which the substance was used) were modeled as categorical outcomes with a Poisson distribution (with adjustment for over-dispersion). With a two time-point design, we did not predict the presence of meaningful variation in the random effect for the slope. Indeed, data simulations have indicated that linear random effects were able to be estimated only $60 \%$ of the time when drawing from a population where linear growth existed (King et al., 2018). Therefore, in line with our hypotheses and to avoid problems with convergence, we did not test the linear random effect and treated the time slope at Level 2 as a fixed effect. The model, therefore, is similar to a repeated-measures ANOVA; however, benefits of using multilevel modeling are that individuals with missing data are retained in analyses and the models can handle non-normally distributed outcomes.

Each outcome variable was tested in a moderation model to examine the extent to which within-person change in adjustment from the baseline assessment to the period of COVID-19 disruptions differed between participants based on their reported loneliness, financial strain, health-related anxiety (both general worry and worry about the negative consequences of illness), alcohol problems, and marijuana craving. Specifically, all 6 moderators (centered) were simultaneously added as predictors of the intercept (i.e., main effect of moderator) and the linear change slope (i.e., change X moderator interaction) at Level 2. Given that the model used to estimate the direct effects was a subset of the moderation model, fit statistics can be employed to determine whether adding the moderators provided a better fit to the data. For each outcome's nested models, the difference between the two deviance parameters was calculated and evaluated 
against the $\chi^{2}$ distribution (Luke, 2020). We probed significant interaction effects (Preacher et al., 2006). Simple slope analyses were conducted by plotting the moderator at $-1 S D$ and $+1 S D$ from the mean to represent lower and higher levels, respectively.

We used the False Discovery Rate (FDR; Benjamini \& Hochberg, 1995) with $\alpha=0.05$ to account for conducting primary hypothesis tests across multiple models of adjustment outcomes. Effect sizes $(d \mathrm{~s})$ were calculated as absolute values using $\left.\left.\sqrt{\left(t^{2} /\left(t^{2}+d f\right.\right.}\right)\right)$ and evaluated as small (0.20), medium (0.50), and large (0.80) (Cohen, 1988). The analysis plan was preregistered on the Open Science Framework (https://osf.io/ztnmq/).

\section{Results}

\section{Preliminary Results}

Descriptive statistics of main study variables are shown in Table 1. Exploratory tests compared possible sex differences in male and female participants' affect and substance use in daily life (6 per assessment), with four reliable differences identified. At baseline, males reported significantly higher levels of positive affect than females, $t(293)=3.43, p=.001$, whereas females reported greater occurrence of prescription misuse in daily life, $t(257.18)=-2.26, p=$ .025. At the COVID-19 assessment, males reported higher levels of positive affect, $t(293)=3.52$, $p=.001$, and lower levels of negative affect, $t(191.22)=-3.09, p=.002$, as compared to females.

Other outcomes were not significantly different for males versus females ( $p$-values $>.12$ ).

Table 2 presents results from testing differences between the risk and non-risk group participants along their affect and substance use outcomes in daily life and their risk factors during the COVID-19 disruption period. Consistent with the sampling strategy, the risk group participants reported significantly greater use of substances in daily life during baseline and the COVID-19 assessments (i.e., higher daily use of alcohol, marijuana, nicotine, and prescription 
drug misuse across both time points). Participants in the two groups did not differ in terms of their reported negative affect or their positive affect in daily life during the baseline and COVID19 assessments. The risk and non-risk participants did not differ on the hypothesized moderators of loneliness, financial strain, health anxiety, and negative consequences of illness. However, the risk group participants continued to endorse more substance-related outcomes, as reflected by their relatively higher levels of alcohol consequences and marijuana craving. Overall, substance use was prevalent, with $90.2 \%$ and $90.5 \%$ of the participants, respectively, reporting use of one or more substances in daily life during the baseline and COVID-19 assessments.

Indicators of substance use in daily life collected during the study baseline period were tested in relation to measures of background substance use and problems completed at the first study session. Alcohol use in daily life was positively linked with background alcohol-related consequences on the RAPI, $r(295)=.28, p<.001$. Nicotine use in daily life was positively linked with lifetime number of cigarettes among participants who had endorsed ever smoking, $r(177)=.27,<.001$. Marijuana use in daily life was positively related to drug problems on the DAST-10 for other drugs, which included marijuana use, $r(295)=.45, p<.001$. Prescription drug misuse in daily life was positively linked to drug problems on the DAST-10 for nonmedical use of prescriptions, $r(295)=.45, p<.001$. Together, these reliable links between substance use in daily life and background level of use/problems associated with the same substance behavior bolster the construct validity of EMA-derived daily life indicators of substance use for analysis.

\section{Direct Results}

Results from the multilevel models testing mean differences in adjustment before and during the early phase of the pandemic are presented in Table 3. Several hypothesized direct changes in young adults' affect and substance behaviors in daily life, accounting for number of 
days between a participant's baseline and COVID-19 assessments (i.e., time elapsed) and risk group status, emerged. Relative to reports collected during the normative period (at baseline), participants experienced significantly higher levels of negative affect, $b=2.86, S E=0.19, p<$ $.001, d=.67$, and were significantly more likely to use alcohol, $b=1.10, S E=0.06, p<.001, d=$ .75 , and marijuana, $b=0.72, S E=0.06, p<.001, d=.58$, in daily life during COVID-19 disruptions. In contrast to our hypothesis, we did not identify direct changes in young adults' positivity, $b=-0.17, S E=0.13, p=.20, d=.07$, nicotine use, $b=0.01, S E=0.07, p=.88, d=$ .01 , or prescription drug misuse, $b=0.007, S E=0.17, p=.97, d=.003$, in daily life across time.

\section{Moderator Results}

Next, we tested 6 potential moderators of changes in adjustment from the normative period to the time of the COVID-19 pandemic, including loneliness, financial strain, worry about health, worry about the negative consequences of illness, alcohol problems, and marijuana cravings. Moderators were tested simultaneously and models retained the covariates of time elapsed between assessments and risk group status. All results from the moderator tests are shown in Table 4, and sample plots are presented in figures to facilitate interpretation.

Changes in negative affect were moderated by 2 of the 6 hypothesized moderators, whereas changes in positive affect in daily life were not moderated by the risk factors (see Table 4). Results from the negative affect model indicated that the increase in negative affect in daily life was significantly greater for individuals reporting (a) higher loneliness, $b=1.00, S E=0.07$, $p<.001, d=.60$, compared to those with lower loneliness, $b=0.43, S E=0.05, p<.001, d=.46$ (see Fig. 1); and (b) higher levels of worry about health, $b=0.99, S E=0.07, p<.001, d=.57$, compared to those with lower levels of worry about health, $b=0.44, S E=0.06, p<.001, d=.43$. These findings were in line with the hypothesized direction of the risk factors. 
In terms of moderators of substance use changes over time, several moderators emerged as significant in models that estimated marijuana use and nicotine use in daily life (see Table 4). In contrast, changes in young adults' alcohol use and prescription drug misuse in daily life were not reliably moderated by any of the hypothesized psychosocial risk factors.

Results from the model that estimated marijuana as the outcome indicated that marijuana use in daily life increased over time for individuals reporting higher levels of financial strain, $b=$ $0.80, S E=0.10, p<.001, d=.41$, compared to those with lower levels of financial strain, $b=$ $0.45, S E=0.03, p<.001, d=.23$ (Fig. 2). Marijuana use in daily life also increased over time for individuals reporting higher levels of marijuana craving, $b=0.75, S E=0.06, p<.001, d=.59$, compared to those with lower levels of marijuana craving, $b=0.49, S E=0.13, p<.001, d=.21$. These findings were consistent with the hypothesized direction of the moderating risk factors.

Results from the nicotine model indicated that nicotine use in daily life decreased over time for individuals experiencing higher levels of loneliness, $b=-0.28, S E=0.12, p=.03, d=$ .13 , and increased for those with lower levels of loneliness during the disruption period, $b=0.18$, $S E=0.08, p=.03, d=.13$. These findings suggest that feeling relatively disconnected from others and having less opportunity to engage with others in enjoyable activities early in the pandemic protected individuals from increased nicotine use over time and were in the opposite direction of the hypothesized moderation. Nicotine use in daily life increased over time for individuals experiencing greater financial strain at the time of COVID-19 disruptions, $b=0.23$, $S E=0.11, p=.04, d=.12$, whereas nicotine use decreased over time for those experiencing less financial strain during the disruption period, $b=-0.33, S E=0.10, p=.001, d=.12$; this finding is consistent with hypothesized moderation effects. 
Together, moderation of substance behaviors indicated greater use of the substance outcomes in daily life at higher levels of the risk factors (i.e., increased marijuana and nicotine use at higher levels of financial strain, increased marijuana use at higher levels of marijuana craving), except in the case of decreased nicotine use among individuals experiencing greater loneliness at the time of the onset of COVID-19 disruptions.

\section{Discussion}

The study examined changes in young adults' adjustment in daily life using prospectively collected data drawn from normative baseline assessments to reports obtained during the early period of COVID-19 disruptions in the United States. Scholars and policy makers have anticipated mental health distress and problematic alcohol use in response to the ongoing pandemic and associated changes to typical life. Our study aligns with these predictions and other initial research (Lechner et al., 2020), by documenting significant increases in young adults' negative affect, alcohol use, and marijuana use in daily life. In contrast to our hypothesis, positive affect, nicotine use, and prescription misuse did not evidence direct changes across time.

On average, negative affect increased among participants from one time-point to the next - a change not typically reported in studies of normative college development (e.g., Finch et al., 2012) - and this increase was particularly elevated among young adults who reported higher levels of loneliness and worry about their health. These and other early results (Son et al., 2020) clearly signal the mental health risks for young adults navigating the COVID-19 disruptions, in a population whose adjustment is deemed critical to later emotional and physical health and wellbeing. It is imperative for future research to track changes in individuals' daily affect levels over time and examine their potential for longer-term mental health consequences. 
The documented direct increases in substance use are significant for several reasons. Alcohol and marijuana are among the most commonly used substances by U.S. college students nationwide (Schulenberg et al., 2019). Notably, the participants were recruited when 91.5\% were under 21 years of age (modal age $=19$ ) and from a state that did not have legal use of marijuana at the time of either assessment. Given the constraints that stemmed from the need to adapt an existing investigation and obtain directly comparable measures during the challenging time of an emerging pandemic, our measures of substance use in daily life focused on frequency of use and did not account for amount of the substance consumed. However, their significance was bolstered by reliable links between baseline daily behaviors and higher levels of relevant substance-related problems. Our findings that showed a prospective increase in alcohol use align with other early research on drinking levels in the pandemic (Lechner et al., 2020).

Marijuana use also increased over time, and to a greater extent among young adults with higher marijuana craving at the onset of COVID-19. This is the first study we are aware of to document elevated marijuana use in response to the pandemic. Given potential adverse effects of marijuana on mental and physical health (Karila et al., 2014; Pujazon-Zarik \& Park, 2009), continued work is needed to assess use of the substance in daily life following the initial period of COVID-19 disruptions and their implications. Indeed, one study found that women's marijuana use predicted their increased psychological distress 8 years later (Danielsson et al., 2016). Enduring elevations of these substances in daily life - directly and interacting with risk factors - could be shown to be problematic, given the predictive nature of these behaviors in early adulthood for later coping styles, drug use disorders, and health (Hall et al., 2016).

Marijuana and nicotine use showed consistent interactive patterns with financial strain, with the behaviors increasing in daily life across time for those with greater financial strain 
during COVID-19 disruptions, as compared to those with lower financial strain. Unfortunately, the current study was not able to disentangle differences in types of nicotine use (e.g., vaping, cigarette use, smokeless tobacco) due to the broad measurement employed. Nevertheless, these moderation findings hold particular risk for young adults with financial strain in light of the heightened threat smoking poses in the context of a virus that attacks the lungs and respiratory health. Indeed, early evidence indicates that smoking increases the likelihood of COVID-19 infection and of having a worse progression of the illness (Vardavas \& Nikitara, 2020).

An unexpected moderation result was that nicotine use in daily life decreased over time for individuals experiencing higher (vs. lower) levels of loneliness during the disruption period. We suspect that this finding indicates a loss of opportunity for "social smoking" (Song \& Ling, 2011) among those young adults who were not in their typical situations early in the COVID-19 disruption period (e.g., returned to their family home), particularly since our background smoking history revealed that a substantial number of smokers in the sample were not heavy smokers. This finding should be interpreted with caution, however, as model comparison results suggest that the moderation model was not particularly robust and may not contribute more to our understanding of changes in young adults' nicotine use beyond the direct effects test alone.

Although understanding the occurrence of prescription drug misuse in daily life is the focus of the broader study for which the participants were recruited, we observed relatively low levels of the behavior, on average, at either assessment point. This is consistent with other college-based studies showing medication misuse to be less frequent than marijuana and alcohol use (e.g., Palmer et al. 2012). Rather, prescription stimulant misuse (the most common type of misuse) has been found to be more closely connected to particular academic periods and motivations (e.g., finals week, Moore et al., 2014; improving grades, Judson \& Langdon, 2009). 
Notwithstanding the relatively low daily rates of the behavior, continued investigation is needed into potentially changing patterns, and implications, of prescription misuse in this context as many young adults are likely to face pandemic strain and disruptions associated with academics.

\section{Implications of the Present Study}

Results from this study offer timely, novel, and translatable information about the risk of young-adult college students' increasing hazardous adjustment in daily life in response to the early phases of the COVID-19 situation during a developmental period that sets the foundation for later adult health. Persistent challenges of mental health distress and substance misuse and abuse facing college campuses are only expected to intensify as a result of the pandemic. Interventions can be designed to reduce negative effects of psychosocial risk factors for mental health distress and alcohol and drug misuse (Hawkins et al., 1992). College professionals who support academics and student wellness should target the psychosocial factors that place some young adult college students at risk for greater affective and behavioral health challenges.

\section{Limitations and Future Directions}

The results should be evaluated in the context of the study's strengths and limitations. The sample is relatively large, and retention was high across the two assessments, but participants were drawn from a study based at a single large public university in the Midwestern United States. The findings may not be applicable to young adults at other types of institutions, although earlier research reported alcohol abuse indicators are relatively similar across college types (Knight et al., 2002). Replication with young adults along diverse racial, ethnic, geographic, and other socio-cultural characteristics remains important. We elected to include available data from all participants in our ongoing study, in order to maximize information 
examined early in the pandemic. Future research should identify factors (e.g., not enrolled vs. enrolled in college) associated with varying experiences at the time of COVID-19 disruptions.

Due to the pressing nature and demands of the pandemic disruptions, we rapidly administered the COVID-19 assessment. Although the data reflect participants' immediate experiences, we did rely on retrospective reports aggregated across the past 14 days for some measures, which is not ideal but was necessary to facilitate comparisons. The moderators were only assessed at the COVID-19 assessment, which is consistent with our focus on vulnerabilities at the height of the pandemic disruptions, yet hampers examination of whether these characteristics changed over time or reflect more stable constructs. Our assessment of financial strain at a single time point may be particularly limited, given the drastic impact of the ongoing health crisis on the economic situation, as well as our lack of available information on parental or family contributions to the young adults' financial situations. By combining respondents' interrelated hardship rating with their financial strain checklist we reduce reliance on any single measure, although future research is encouraged to collect detailed information about young adults' particular financial contexts (Serido et al., 2014). In addition, with no control group in the study design (i.e., young adults who did not experience the pandemic), we cannot draw causal conclusions. Clearly, it will be critical to study ongoing pandemic-related impacts over time.

Taken together, the current findings provide early documentation for adverse effects of the COVID-19 pandemic on young adults' affect and substance use behavior. The findings also underscore the importance of dedicating efforts to strengthening social connection, reducing financial stress and worry about health, and devoting attention to young adults with elevated substance tendencies in order to promote better adjustment outcomes and maintain health during this unmatched crisis period and beyond. 


\section{References}

Benjamini, Y., \& Hochberg, Y. (1995). Controlling the false discovery rate: A practical and powerful approach to multiple testing. Journal of the Royal Statistical Society. Series B (Methodological), 57, 289-300. https://doi.org/10.1111/j.2517-6161.1995.tb02031.x

Bronfenbrenner, U., \& Morris, P. A. (2006). The bioecological model of human development. In R. M. Lerner \& W. Damon (Eds.), Handbook of child psychology: Theoretical models of human development (6 ${ }^{\text {th }}$ ed., Vol. 1, pp. 793-828). John Wiley \& Sons.

Brown, S. A., McGue, M., Maggs, J. L., Schulenberg, J., Hingson, R., Swartzwelder, S., Martin, C., Chung, T., Tapert, S. F., Sher, K., Winters, K. C., Lowman, C., \& Murphy, S. (2008). A developmental perspective on alcohol and youths 16 to 20 years of age. Pediatrics, 121, S290-S310. https://doi.org/10.1542/peds.2007-2243D

Cao, W., Fang, Z., Hou, G., Han, M., Xu, X, Dong, J., \& Zheng, J. (2020). The psychological impact of the COVID-19 epidemic on college students in China. Psychiatry Research, 287, Article 112934. https://doi.org/10.1016/j.psychres.2020.112934

Cella, D., Riley, W., Stone, A., Rothrock, N., Reeves, B., Yount, S., Amtmann, D., Bode, R., Buysse, D., Choi, S., Cook, K., DeVellis, R., DeWalt, D., Fries, J. F., Gershon, R., Hahn, E. A., Lai, J-S., Pilkonis, P., Revicki, D.,...PROMIS Cooperative Group. The Patientreported Outcomes Measurement Information System (PROMIS) developed and tested its first wave of adult self-reported health outcome item banks: 2005-2008. Journal of Clinical Epidemiology, 63, 1179-1194. https://doi.org/10.1016/j.jlinepi.2010.04.011

Clay, J. M., \& Parker, M. O. (2020). Alcohol use and misuse during the COVID-19 pandemic: a potential public health crisis? The Lancet Public Health. https://doi.org/10.1016/S2468$\underline{2667(20) 30088-8}$ 
Cohen, J. (1988). Statistical power analysis for the behavioral sciences ( $2^{\text {nd }}$ ed.). Erlbaum.

Cranford, J. A., Shrout, P. E., Iida, M., Rafaeli, E., Yip, T., \& Bolger, N. (2006). A procedure for evaluating sensitivity to within-person change: Can mood measures in diary studies detect change reliably? Personality and Social Psychology Bulletin, 32, 917-929. https://doi.org/10.1177/0146167206287721

Danielsson, A-K., Lundin, A., Allebeck, P., \& Agardh, E. (2016). Cannabis use and psychological distress: An 8-year prospective population-based study among Swedish men and women. Addictive Behaviors, 59, 18-23. https://doi.org/10.1016/j.addbeh.2016.03.005

Dixit, A. R., \& Crum, R. M. (2000). Prospective study of depression and risk of heavy alcohol use in women. American Journal of Psychiatry, 157, 751-758. https://doi.org/10.1176/appi.ajp.157.5.751

Finch, J. F., Baranik, L. E., Liu, Y., \& West, S. G. (2012). Physical health, positive and negative affect, and personality: A longitudinal analysis. Journal of Research in Personality, 46, 537-545. https://doi.org/10.1016/j.jrp.2012.05.013

Greene, K. M., \& Maggs, J. L. (2017). Academic time during college: Associations with mood, tiredness, and binge drinking across days and semesters. Journal of Adolescence, 56, 2433. https://doi.org/10.1016/j.adolescence.2016.12.001

Gruber, J., Prinstein, M. J., Abramowitz, J. S., Albano, A. M., Aldao, A., Borelli, J. L., Chung, T., Clark, L. A., Davila, J., Forbes, E. E., Gee, D. G., Nagayama Hall, G. C., Hallion, L. S., Hinshaw, S. P., Hoffman, S. G., Hollon, S. D., Joormann, J., Kazdin, A. E., Klein, D. N.,...Weinstock, L. M. (2020). Mental health and clinical psychological science in the 
time of COVID-19: Challenges, opportunities, and a call to action. https://doi.org/10.31234/osf.io/desg9

Hall, W. D., Patton, G., Stockings, E., Weier, M., Lynskey, M., Morely, K. I., \& Degenhardt, L. (2016). Why young people's substance use matters for global health. Lancet Psychiatry, 3, 265-279. https://doi.org/10.2016/S2215-0366(16)00013-4

Hawkins, J. D., Catalano, R. F., \& Miller, J. Y. (1992). Risk and protective factors for alcohol and other drug problems in adolescence and early adulthood: Implications for substance abuse prevention. Psychological Bulletin, 112, 64-105. https://doi.org/10.1037/0033$\underline{2909.112 .1 .64}$

Heishman, S. J., Evans, R. J., Singleton, E. G., Levin, K. H., Copersino, M. L., \& Gorelick, D. A. (2009). Reliability and validity of a short form of the Marijuana Craving Questionnaire. Drug and Alcohol Dependence, 102, 35-40. https://doi.org/10.1016/j.drugalcdep.2008.12.010

Jaremka, L. M., Sunami, N., \& Nadzan, M. A. (2017). Eating moderates the link between body mass index and perceived social connection. Appetite, 112, 124-132. https://doi.org/10.1016/j.appet.2017.01.016

Jennison, K. M. (2004). The short-term effects and unintended long-term consequences of binge drinking in college: A 10-year follow-up study. American Journal of Drug and Alcohol Abuse, 30, 659-684. https://doi.org/10.1081/ADA-200032331

Judson, R., \& Langdon, S. W. (2009). Illicit use of prescription stimulants among college students: Prescription status, motives, theory of planned behavior, knowledge and selfdiagnostic tendencies. Psychology, Health \& Medicine, 14, 97-104. https://doi.org/10.1080/13548500802126723 
Karila, L., Roux, P., Rolland, B., Benyamina, A., Reynaud, M., Aubin, H-J., \& Lancon, C. (2014). Acute and long-term effects of cannabis use: A review. Current Pharmaceutical Design, 20, 4112-4118. https://doi.org/10.2174/13816128113199990620

Kiely, K. M., Leach, L. S., Olesen, S. C., \& Butterworth, P. (2015). How financial hardship is associated with the onset of mental health problems over time. Social Psychiatry and Psychiatry Epidemiology, 50, 909-918. https://doi.org/10.1007/s00127-015-1027-0

King, K. M., Littlefield, A. K., McCabe, C. J., Mills, K. L., Flournoy, J., \& Chassin, L. (2018). Longitudinal modeling in developmental neuroimaging research: Common challenges, and solutions from developmental psychology. Developmental Cognitive Neuroscience, 33, 54-72. https://doi.org/10.1016/j.den.2017.11.009

Knight, J. R., Wechsler, H., Kuo, M., Seibring, M., Weitzman, E. R., \& Schuckit, M. A. (2002). Alcohol abuse and dependence among U.S. college students. Journal of Studies on Alcohol, 63, 263-270. https://doi.org/10.15288/jsa.2002.63.263

Lechner, W. V., Lauren, K. R., Patel, S., Grega, C., \& Kenne, D. R. (2020). Changes in alcohol use as a function of psychological distress and social support following COVID-19 related University closings. Addictive Behaviors. https://doi.org/10.1016/j.addbeh.2020.106527

Lee, T. K., Wickrama, K. A. S., Kwon, J. A., Lorenz, F. O., \& Oshri, A. (2017). Antecedents of transition patterns of depressive symptom trajectories from adolescence to young adulthood. British Journal of Developmental Psychology, 35, 498-515. https://doi.org/10.1111/bjdp.12189

Linden-Carmichael, A. N., Braitman, A. L., \& Henson, J. M. (2015). Protective behavioral strategies as a mediator between depressive symptom fluctuations and alcohol 
consumption: A longitudinal examination among college students. Journal of Studies on Alcohol and Drugs, 76, 80-88. https://doi.org/10.15288/jsad.2015.76.80

Luke, D. A. (2020). Multilevel modeling ( $2^{\text {nd }}$ ed.). Sage Publications.

Maddock, J. E., Laforge, R. G., Rossi, J. S., \& O’Hare, T. (2001). The College Alcohol Problems Scale. Addictive Behaviors, 26, 385-398. https://doi.org/10.1016/S0306-4603(00)00116-7

Metzger, I. W., Blevins, C., Calhoun, C. D., Ritchwood, T. D., Gilmore, A. K., Stewart, R., \& Bountress, K. E. (2017). An examination of the impact of maladaptive coping on the association between stressor type and alcohol use in college. Journal of American College Health, 65, 534-541. https://doi.org/10.1080/07448481.2017.1351445

Moore, D. R., Burgard, D. A., Larson, R. G., \& Ferm, M. (2014). Psychostimulant use among college students during periods of high and low stress: An interdisciplinary approach utilizing both self-report and unobtrusive chemical sample data. Addictive Behaviors, 39, 987-993. https://doi.org/10.1016/j.addbeh.2014.01.021

Morley, K. I., Ferris, J. A., Winstock, A. R., \& Lynskey, M. T. (2017). Polysubstance use and misuse or abuse of prescription opioid analgesics: a multi-level analysis of international data. Pain, 158, 1138-1144. https://doi.org/10.1097/j.pain.0000000000000892

National Institutes of Health (2013). U.S. Food and Drug Administration. Population Assessment of Tobacco and Health (PATH) Study: Final Adult Baseline (Wave 1) Questionnaire. National Institutes of Health.

Neal, D. J., Corbin, W. R., \& Fromme, K. (2006). Measurement of alcohol-related consequences among high school and college students: Application of item response models to the Rutgers Alcohol Problem Index. Psychological Assessment, 18, 402-414. https://doi.org/10.1037/1040-3590.18.4.402 
Palmer, R. S., McMahon, T. J., Moreggi, D. I., Rounsaville, B. J., \& Ball, S. A. (2012). College student drug use: Patterns, concerns, consequences, and interest in intervention. Journal of College Student Development, 53, 124-132. https://doi.org/10.1353/csd.2012.0014

Papp, L. M., Barringer, A., Blumenstock, S. M., Gu, P., Blaydes, M., Lam, J., \& Kouros, C. D. (2020). Development and acceptability of a method to investigate prescription drug misuse in daily life: An ecological momentary assessment study. JMIR Mhealth and Uhealth, 8(10), e21676. https://doi.org/10.2196/21676

Papp, L. M., Kouros, C. D., \& Curtin, J. J. (2020). Real-time associations between young adults' momentary pain and prescription opioid misuse intentions in daily life. American Psychologist, 75, 761-771. https://doi.org/10.1037/amp0000648

Preacher, K. J., Curran, P. J., \& Bauer, D. J. (2006). Computational tools for probing interactions in multiple linear regression, multilevel modeling, and latent curve analysis. Journal of Educational and Behavioral Statistics, 31, 437-448. https://doi.org/10.3102/10769986031004437

Pujazon-Zazik, M., \& Park, M. J. (2009). Marijuana: Use among males and health outcomes. American Journal of Men's Health, 3, 265-274. https://doi.org/10.1177/1557988309340577

Raudenbush, S. W., Bryk, A. S., Cheong, Y. F., \& Congdon, R. (2019). HLM 8 for Windows [Computer software]. Scientific Software International, Inc.

Rodriguez, L. M., Litt, D. M., \& Stewart, S. H. (2020). Drinking to cope with the pandemic: The unique associations of COVID-19-related perceived threat and psychological distress to drinking behaviors in American men and women. Addictive Behaviors. https://doi.org/10.1016/j.addbeh.2020106532 
Salkovskis, P. M., Rimes, K. A., Warwick, H. M. C., \& Clark, D. M. (2002). The Health Anxiety Inventory: Development and validation of scales for the measurement of health anxiety and hypochondriasis. Psychological Medicine, 32, 843-853. https://doi.org/10.1017/S0033291702005822

Sarginson, J. E., Deakin, J. F. W., Anderson, I. M., Downey, D., Thomas, E., Elliott, R., \& Juhasz, G. (2014). Neuronal nitric oxide synthase (NOS1) polymorphisms interact with financial hardship to affect depression risk. Neuropsychopharmacology, 39, 2857-2866. https://doi.org/10.1038/npp.2014.137

Schulenberg, J. E., Johnston, L. D., O’Malley, P. M., Bachman, J. G., Miech, M. E., \& Patrick, M. E. (2019). Monitoring the Future National Survey Results on Drug Use, 1975-2018: Volume II: College Students and Adults Ages 19-60. Ann Arbor, MI.

Serido, J., Shim, S., Xiao, J. J., Tang, C., \& Card, N. A. (2014). Financial adaptation among college students: Helping students cope with financial strain. Journal of College Student Development, 55, 310-316. https://doi.org/10.1353/csd.2014.0032

Skinner, H. (1982). The Drug Abuse Screening Test. Addictive Behaviors, 7, 363-371. https://doi.org/10.1016/0306-4603(82)90005-3

Son, C., Hegde, S., Smith, A., Wang, X., \& Sasangohar, F. (2020). Effects of COVID-19 on college students' mental health in the United States: Interview survey study. Journal of Medical Internet Research, 22, e21279. https://doi.org/10.2196/21279

Song, A. V., \& Ling, P. M. (2011). Social smoking among young adults: Investigation of intentions and attempts to quit. American Journal of Public Health, 101, 1291-1296. https://doi.org/10.2105/AJPH.2010.300012 
Stroud, C., Walker, L. R., Davis, M., \& Irwin, Jr., C. E. (2015). Investing in the health and wellbeing of young adults. Journal of Adolescent Health, 56, 127-129. https://doi.org/10.1016/j.jadohealth.2014.11.012

Twenge, J. M., \& Joiner, T. E. (2020). Mental distress among U.S. adults during the COVID-19 pandemic. https://doi.org/10.31234/osf.io/wc8ud

Vardavas, C. I., \& Nikitara, K. (2020). COVID-19 and smoking: A systematic review of the evidence. Tobacco Induced Diseases, 18. https://doi.org/10.18332/tid/119324

Vinkers, C. H., van Amelsvoort, T., Bisson, J. I., Branchi, I., Cryan, J. F., Domschke, K., Howes, O. D., Manchia, M., Pinto, L., de Quervain, D., Schmidt, M. V., \& van der Wee, N. J. A. (2020). Stress resilience during the coronavirus pandemic. European Neuropsychopharmacology, 35, 12-16. https://doi.org/10.1016/i.euroneuro.2020.05.003

Watson, D., \& Clark, L. A. (1999). The PANAS-X: Manual for the Positive and Negative Affect Schedule-Expanded Form. Unpublished manuscript, University of Iowa.

White, B. P., Becker-Blease, K. A., \& Grace-Bishop, K. (2006). Stimulant medication use, misuse, and abuse in an undergraduate and graduate student sample. Journal of American College Health, 54, 261-268. https://doi.org/10.3200/JACH.54.5.261-268

White, H. R., \& Labouvie, E. W. (1989). Towards the assessment of adolescent problem drinking. Journal of Studies on Alcohol, 50, 30-37. https://doi.org/10.15288/jsa.1989.50.30 
Table 1

Descriptive Statistics for Key Study Variables

\begin{tabular}{|c|c|c|c|}
\hline & $M$ & $S D$ & Range \\
\hline \multicolumn{4}{|l|}{$\begin{array}{l}\text { Background substance use problems at } \\
\text { baseline }\end{array}$} \\
\hline RAPI & 3.36 & 3.12 & $0-14$ \\
\hline Lifetime cigarette use & 2.50 & 1.56 & $1-6$ \\
\hline DAST-10 prescription drug misuse & 1.54 & 1.60 & $0-10$ \\
\hline DAST-10 other drugs & 2.00 & 1.84 & $0-9$ \\
\hline \multicolumn{4}{|l|}{ Affect and Substance Use in Daily Life } \\
\hline Baseline negative affect & 5.63 & 1.63 & $4-12.55$ \\
\hline Baseline positive affect & 7.98 & 2.11 & $3.10-14.37$ \\
\hline Baseline alcohol $^{\mathrm{a}}$ & .11 & .11 & $0-.75$ \\
\hline Baseline marijuana $^{\mathrm{a}}$ & .12 & .19 & $0-.94$ \\
\hline Baseline nicotine $^{\mathrm{a}}$ & .20 & .29 & $0-1$ \\
\hline Baseline prescription drug misuse ${ }^{\mathrm{a}}$ & .03 & .07 & $0-.58$ \\
\hline COVID-19 negative affect & 8.49 & 3.34 & $4-20$ \\
\hline COVID-19 positive affect & 7.81 & 1.69 & $3-12$ \\
\hline COVID-19 alcohol $^{\mathrm{a}}$ & .33 & .27 & $0-1$ \\
\hline COVID-19 marijuana $^{a}$ & .24 & .35 & $0-1$ \\
\hline COVID-19 nicotine $^{\mathrm{a}}$ & .20 & .34 & $0-1$ \\
\hline COVID-19 prescription drug misuse ${ }^{a}$ & .03 & .09 & $0-1$ \\
\hline \multicolumn{4}{|l|}{ Risk factors at COVID-19 assessment } \\
\hline Loneliness & 30.80 & 9.94 & $14-62$ \\
\hline Financial strain & .00 & 1.83 & $-2.15-6.08$ \\
\hline Health anxiety & 27.40 & 6.65 & $15-56$ \\
\hline Negative consequences of illness & 6.92 & 2.06 & $4-16$ \\
\hline Alcohol consequences & 1.03 & 1.39 & $0-5$ \\
\hline Marijuana craving & 15.81 & 8.38 & $6-42$ \\
\hline
\end{tabular}

Note. RAPI = Rutgers Alcohol Problem Index; DAST-10 = 10-item Drug Abuse Screening Test.

${ }^{a}$ Indicators were scored as the proportion of days on which the substance was used. 
Table 2

Risk Factors and Adjustment in Daily Life: Differences in Risk and Non-risk Participants

\begin{tabular}{lccc}
\hline & $\begin{array}{c}\text { Risk } \\
n=250\end{array}$ & $\begin{array}{c}\text { Non-risk } \\
n=45\end{array}$ & $\begin{array}{c}\text { Difference } \\
\text { between subgroups }\end{array}$ \\
\hline Affect and Substance Use in Daily Life & $M(S D)$ & $M(S D)$ & Statistical comparison \\
Baseline negative affect & $5.63(1.61)$ & $5.64(1.73)$ & $t(291)=-.03$ \\
Baseline positive affect & $8.03(2.08)$ & $7.70(2.26)$ & $t(291)=.95$ \\
Baseline alcohol & $.12(.11)$ & $.06(.07)$ & $t(89.01)^{\mathrm{a}}=4.82^{* *}$ \\
Baseline marijuana & $.13(.20)$ & $.04(.09)$ & $t(132.56)^{\mathrm{a}}=5.25^{* *}$ \\
Baseline nicotine & $.23(.30)$ & $.04(.14)$ & $t(128.79)^{\mathrm{a}}=6.98^{* *}$ \\
Baseline prescription drug misuse & $.03(.07)$ & $.003(.02)$ & $t(253.0)^{\mathrm{a}}=5.31^{* *}$ \\
COVID-19 negative affect & $8.60(3.42)$ & $7.89(2.82)$ & $t(69.46)^{\mathrm{a}}=1.50$ \\
COVID-19 positive affect & $7.78(1.71)$ & $7.96(1.58)$ & $t(293)=-.63$ \\
COVID-19 alcohol & $.35(.27)$ & $.22(.20)$ & $t(77.21)^{\mathrm{a}}=3.92^{* *}$ \\
COVID-19 marijuana & $.27(.36)$ & $.09(.22)$ & $t(92.31)^{\mathrm{a}}=4.56^{* *}$ \\
COVID-19 nicotine & $.23(.35)$ & $.07(.25)$ & $t(78.42)^{\mathrm{a}}=3.61^{* *}$ \\
COVID-19 prescription drug misuse & $.03(.10)$ & $.003(.02)$ & $t(287.56)^{\mathrm{a}}=4.09^{* *}$ \\
Risk factors at COVID-19 assessment & & & \\
Loneliness & $30.52(10.07)$ & $32.38(9.13)$ & $t(293)=-1.15$ \\
Financial strain & $.01(1.87)$ & $-.08(1.61)$ & $t(293)=.33$ \\
Health anxiety & $27.69(6.80)$ & $25.82(5.65)$ & $t(293)=1.73$ \\
Negative consequences of illness & $6.98(2.09)$ & $6.56(1.87)$ & $t(293)=1.27$ \\
Alcohol consequences & $1.11(1.42)$ & $.62(1.15)$ & $t(70.23)^{\mathrm{a}}=2.51^{*}$ \\
Marijuana craving & $16.47(8.36)$ & $12.16(7.56)$ & $t(293)=3.23^{* *}$ \\
\hline
\end{tabular}

${ }^{\text {a }}$ Corrected degrees of freedom due to unequal variances.

$* p<.05 . * * p<.01$. 
Table 3

Direct Changes: Effect of COVID-19 on Young Adults' Affect and Substance Use in Daily Life

\begin{tabular}{|c|c|c|c|c|c|c|}
\hline & $\begin{array}{l}\text { Negative affect } \\
\text { Estimate }(S E)\end{array}$ & $\begin{array}{l}\text { Positive affect } \\
\text { Estimate }(S E)\end{array}$ & $\begin{array}{c}\text { Alcohol use } \\
\text { Estimate }(S E)\end{array}$ & $\begin{array}{l}\text { Marijuana use } \\
\text { Estimate }(S E)\end{array}$ & $\begin{array}{l}\text { Nicotine use } \\
\text { Estimate }(S E)\end{array}$ & $\begin{array}{l}\text { Prescription misuse } \\
\text { Estimate }(S E)\end{array}$ \\
\hline Fixed effects & & & & & & \\
\hline $\begin{array}{l}\text { Level } 1 \text { (time) } \\
\text { Linear change }\end{array}$ & $2.86(0.19) * *$ & $-0.17(0.13)$ & $1.10(0.06)^{* * *}$ & $0.72(0.06)^{* *}$ & $0.01(0.07)$ & $0.01(0.17)$ \\
\hline $\begin{array}{l}\text { Level } 2 \text { (individual } \\
\text { Time elapsed } \\
\text { Risk group } \\
\text { Intercept }\end{array}$ & $\begin{array}{c}0.00009(0.0006) \\
0.36(0.32) \\
\mathbf{5 . 6 3 ( 0 . 1 0 ) * *}\end{array}$ & $\begin{array}{c}-0.001(0.0005)^{*} \\
-0.03(0.24) \\
7.98(\mathbf{0 . 1 2}) * *\end{array}$ & $\begin{array}{c}0.001(0.0002) * * \\
0.59(0.13)^{* *} \\
-2.23(0.06)^{* *}\end{array}$ & $\begin{array}{c}0.0001(0.0004) \\
1.23(0.32)^{* * *} \\
-2.18(0.08)^{* *}\end{array}$ & $\begin{array}{c}0.0002(0.0004) \\
1.48(0.53)^{* * *} \\
-1.67(0.09)^{* *}\end{array}$ & $\begin{array}{c}0.0006(0.0007) \\
2.45(\mathbf{1 . 1 1})^{*} \\
-\mathbf{3 . 7 8}(\mathbf{0 . 2 0})^{* *}\end{array}$ \\
\hline $\begin{array}{l}\text { Random effects } \\
\text { Intercept }^{\mathrm{a}} \\
\text { Level } 1 \text { residual }^{\mathrm{b}}\end{array}$ & $\begin{array}{c}\text { Variance } \\
1.74 * * \\
5.14\end{array}$ & $\begin{array}{c}\text { Variance } \\
1.06^{* *} \\
2.52\end{array}$ & $\begin{array}{c}\text { Variance } \\
0.33^{* *} \\
0.08\end{array}$ & $\begin{array}{c}\text { Variance } \\
1.75^{* *} \\
0.09\end{array}$ & $\begin{array}{c}\text { Variance } \\
1.61 * * \\
0.13\end{array}$ & $\begin{array}{c}\text { Variance } \\
2.34^{* *} \\
0.03\end{array}$ \\
\hline
\end{tabular}

Note. Results from population-average models with unstandardized coefficients and robust standard errors are presented. The linear change parameter tests the difference in adjustment indicators from the baseline assessment to the COVID-19 assessment, with a positive coefficient indicating an increase when assessed during COVID-19, as compared to baseline. Time elapsed = number of days between a participant's baseline and COVID-19 assessments. Risk group was coded as $0=$ non-risk, $1=$ risk. Bolded results indicate fixed effects that remained significant after FDR correction for multiple tests.

${ }^{\mathrm{a}} d f=292$ for $\chi^{2}$ test. ${ }^{\mathrm{b}}$ No statistical test was conducted for this parameter.

${ }^{*} p<.05 . * * p<.01$. 
Table 4

Moderation of Changes in Affect and Substance Use in Daily Life

\begin{tabular}{|c|c|c|c|c|c|c|}
\hline & $\begin{array}{l}\text { Negative affect } \\
\text { Estimate }(S E)\end{array}$ & $\begin{array}{l}\text { Positive affect } \\
\text { Estimate }(S E)\end{array}$ & $\begin{array}{c}\text { Alcohol use } \\
\text { Estimate }(S E)\end{array}$ & $\begin{array}{l}\text { Marijuana use } \\
\text { Estimate }(S E)\end{array}$ & $\begin{array}{l}\text { Nicotine use } \\
\text { Estimate }(S E)\end{array}$ & $\begin{array}{c}\text { Prescription } \\
\text { misuse } \\
\text { Estimate }(S E)\end{array}$ \\
\hline \multicolumn{7}{|l|}{ Fixed effects } \\
\hline Linear change & $2.86(0.17)^{* *}$ & $-0.17(0.13)$ & $1.08(0.06)^{* *}$ & $0.62(0.09) * *$ & $-0.05(0.08)$ & $-0.07(0.22)$ \\
\hline Change X Loneliness & $0.07(0.02)^{* *}$ & $0.03(0.02)$ & $-0.003(0.01)$ & $-0.003(0.006)$ & $-0.02(0.01)^{* *}$ & $-0.01(0.02)$ \\
\hline Change X Financial strain & $0.05(0.10)$ & $0.07(0.07)$ & $-0.06(0.03)$ & $0.10(0.03) * *$ & $0.15(0.04) * *$ & $0.03(0.12)$ \\
\hline Change X Health anxiety & $0.09(0.03)^{* *}$ & $0.001(0.02)$ & $0.01(0.01)$ & $0.02(0.009)^{*}$ & $0.005(0.01)$ & $0.03(0.03)$ \\
\hline Change X Health neg. cons. & $0.19(0.09)^{*}$ & $0.06(0.06)$ & $0.04(0.03)$ & $-0.05(0.02)^{*}$ & $0.03(0.03)$ & $-0.08(0.07)$ \\
\hline Change X Alcohol problems & $0.22(0.14)$ & $-0.07(.10)$ & $0.07(0.04)$ & $-0.01(0.04)$ & $0.03(0.05)$ & $0.13(0.14)$ \\
\hline Change X Marijuana craving & $0.02(0.02)$ & $0.02(0.02)$ & $0.003(0.01)$ & $0.02(0.01)^{* *}$ & $0.006(0.008)$ & $0.02(0.03)$ \\
\hline \multicolumn{7}{|l|}{ Model fit vs. direct model } \\
\hline$\Delta$ deviance parameters ${ }^{\mathrm{a}}$ & $199.1 * *$ & $50.4 * *$ & 8.0 & $56.0 * *$ & 13.1 & 1.7 \\
\hline
\end{tabular}

Note. Results from population-average models with unstandardized coefficients and robust standard errors are presented. Only results

for the linear change effect and the change X moderator interactions are presented. The linear change parameter tests the difference in adjustment indicators from the baseline assessment to the COVID-19 assessment, with a positive coefficient indicating an increase when assessed during COVID-19, as compared to baseline. Models included main effects of time elapsed, risk group, and the moderator variables as intercept covariates. Bolded results indicate fixed effects that remained significant after FDR correction for multiple tests.

a $d f=12$ for $\chi^{2}$ test.

$* p<.05 . * * p \leq .01$ 
Figure 1. Young adults' negative affect in daily life before and during COVID-19 disruptions, as moderated by loneliness. $Y$-values reflect the average levels of negative affect reported before the COVID-19 pandemic and at the time of COVID-19 disruptions for participants experiencing less loneliness $(-1 S D)$ vs. more loneliness $(+1 S D)$. Worry about health was also a statistically significant moderator of change in negative affect, and moderating relations for participants reporting less vs. more worry about health were similar to what is shown in the figure. The model controlled for time elapsed between the assessments and study risk group membership. $N$ $=295$ participants.

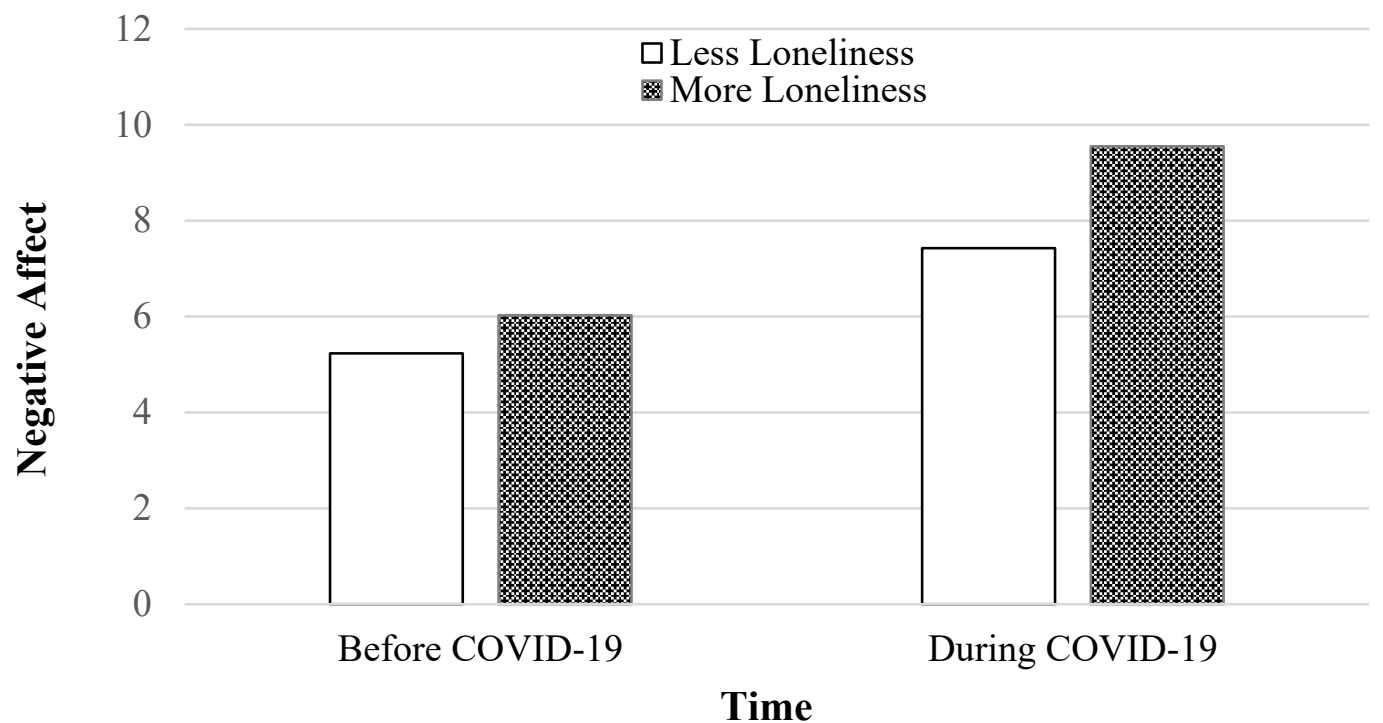


Figure 2. Young adults' marijuana use in daily life before and during COVID-19 disruptions, as moderated by financial strain. $Y$-values reflect the proportion of days of marijuana use reported before the COVID-19 pandemic and at the time of COVID-19 disruptions for participants reporting lower financial strain $(-1 S D)$ vs. higher financial strain $(+1 S D)$. Marijuana craving was also a statistically significant moderator of change in marijuana use, and moderating relations for participants reporting less vs. more marijuana craving were similar to what is shown in the figure. The model controlled for time elapsed between the assessments and study risk group membership. $N=295$ participants.

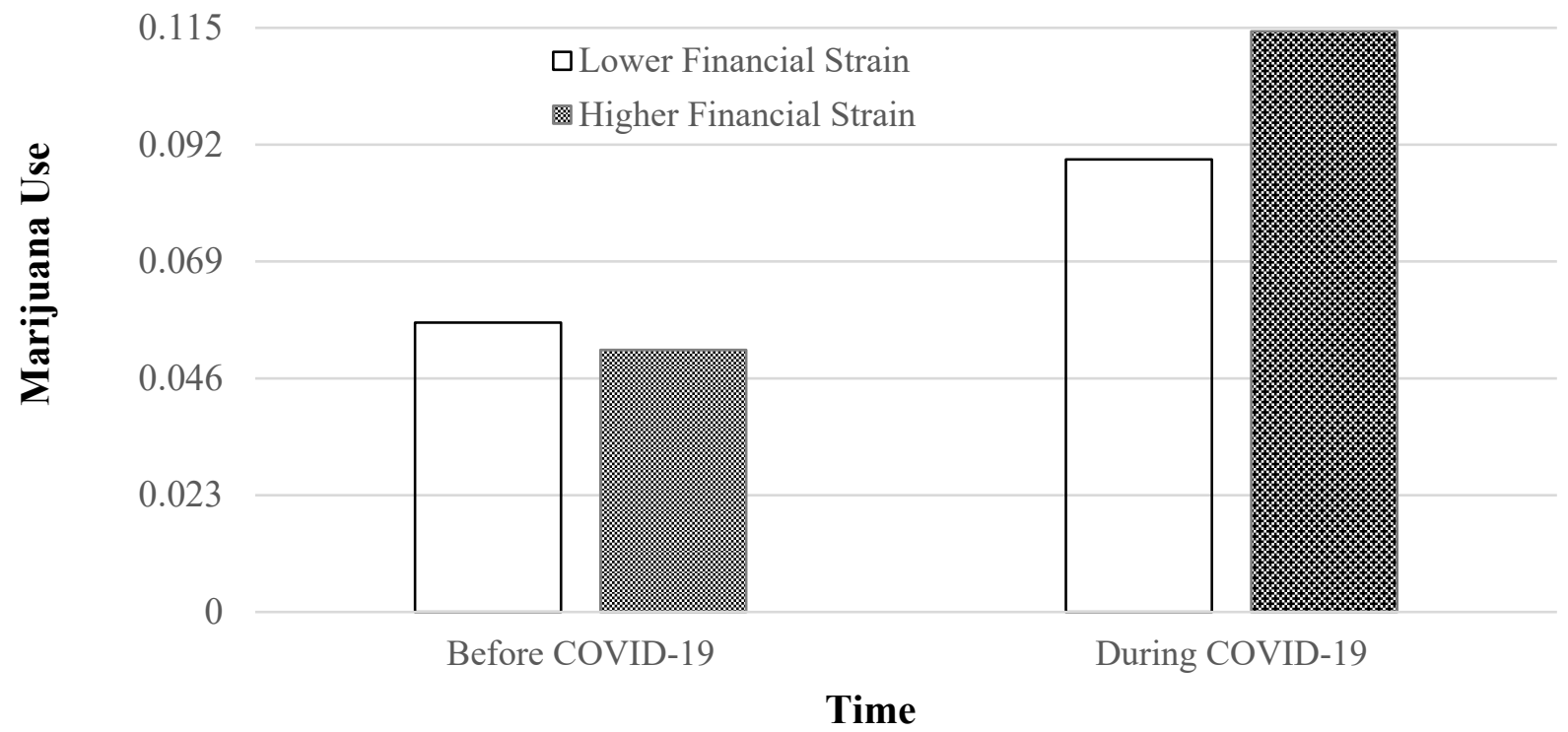

